\title{
The impact of cooking and digestion on the antioxidant capacity and polyphenol content of common culinary spices
}

\author{
I. Baker, M. Chohan and E. I. Opara \\ School of Life Sciences, Kingston University, Kingston upon Thames, KT1 2EE, UK
}

Polyphenols are ubiquitous phytochemicals present in plants and plant derived foods such as spices and their antioxidant properties have been linked to their postulated health benefits ${ }^{(1)}$. Spices are often subjected to both cooking (C) and digestion (D), however, there is little if any data on the impact of these factors on their polyphenolic antioxidant activity. Thus, the extent to which these processes impact the antioxidant capacity (AC) and total phenolic content (TPC) of spices were examined in the present study.

Aqueous control samples and cooked samples of spices $(1 \mathrm{~g}$ cinnamon, $1 \mathrm{~g}$ nutmeg or $0.1 \mathrm{~g}$ clove) were prepared, with cooked samples further subjected to in vitro digestion ${ }^{(2)}$. The ABTS $+\bullet$ decolourisation assay ${ }^{(3)}$ was used to analyse the AC of each sample and expressed as TEAC $\mu \mathrm{mol} / \mathrm{g}$. TPC was determined using Folin-Ciocalteau reagents ${ }^{(4)}$ and was expressed as GAE (mg/g).

Cooking alone did not have a significant impact on the AC of cinnamon, but did increase TPC to a significant $(P<0.05)$ level. The AC of clove was significantly lowered $(P<0.05)$ by $\mathrm{C}$ but was significantly increased $(P<0.05)$ following $\mathrm{C}$ and $\mathrm{D}$. In nutmeg, $\mathrm{C}$ significantly increased $(P<0.05) \mathrm{AC}$, but had no significant impact on TPC. $\mathrm{C}$ and D had no significant impact on either the AC or TPC of cinnamon, yet in nutmeg both variables were significantly increased $(P<0.05)$. The TPC and the AC of clove were significantly higher $(P<0.05)$ following $\mathrm{C}$ and $\mathrm{D}$.

\begin{tabular}{|c|c|c|c|c|}
\hline Spice & TEAC $(\mu \mathrm{mol} / \mathrm{g} ; n 3)$ & SD & $\mathrm{GAE}(\mathrm{mg} / \mathrm{g} ; n 3)$ & $\mathrm{SD}$ \\
\hline Cinnamon, uncooked & 361.2 & 21.5 & 29.8 & 0.6 \\
\hline Cinnamon, cooked & 369.3 & 13.8 & $34.1 *$ & 0.3 \\
\hline Cinnamon, cooked and digested & 386.4 & 27.9 & $34.5 *$ & 0.9 \\
\hline Clove, uncooked & 3487.8 & 20.2 & 296.9 & 9.2 \\
\hline Clove, cooked & $2298.2^{*}$ & 149.6 & 292.0 & 17.1 \\
\hline Clove, cooked and digested & $3228.7 \dagger$ & 320.3 & $341.1 * \dagger$ & 22.1 \\
\hline Nutmeg, uncooked & 37.5 & 1.4 & 1.8 & 0.8 \\
\hline Nutmeg, cooked & $64.8^{*}$ & 1.3 & 6.8 & 0.1 \\
\hline Nutmeg, cooked and digested & $278.1 * \dagger$ & 8.7 & $16.9 * \dagger$ & 4.2 \\
\hline
\end{tabular}

In conclusion, although cooking, and cooking followed by digestion, affected TPC and/or AC this effect was not consistent for the spices investigated and thus no clear relationship emerged. Further work on the impact of these factors on other biological properties of culinary spices is under way.

1. Manach C, Scalbert A, Morand C et al. (2004) Am J Clin Nutr 79, 727-747.

2. Garret DA, Failla ML \& Sarama RJ (1999) J Agric Food Chem 47, 4301-4309.

3. Re R, Pellegrini N, Proteggente A et al. (1999) Free Radic Biol and Med 26, 1231-1237.

4. Stoilova I, Krastanov A, Denev P et al. (2007) Food Chem 102, 764-770. 